EGU21-16591

https://doi.org/10.5194/egusphere-egu21-16591

EGU General Assembly 2021

(c) Author(s) 2021. This work is distributed under

the Creative Commons Attribution 4.0 License.

\title{
Exploring the flow evolution of the Chamoli event (Uttarakhand, India) of 7 February 2021: From geomorphological mapping to multi- model computer simulations
}

Martin Mergilii ${ }^{1}$, Ashim Sattar ${ }^{2}$, Johnathan Carrivick ${ }^{3}$, Adam Emmer ${ }^{1}$, Kyle T. Mandli ${ }^{4}$, Mylène Jacquemart ${ }^{5}$, Scott Watson ${ }^{6}$, Matt Westoby ${ }^{7}$, John J. Clague ${ }^{8}$, Umesh K. Haritashya ${ }^{9}$, and Dan H. Shugar ${ }^{10}$

${ }^{1}$ Cascade - Mountain Processes and Mountain Hazards, Institute of Geography and Regional Science, University of Graz, Austria

${ }^{2}$ Glaciology and Geomorphodynamics, Department of Geography, University of Zurich, Switzerland

${ }^{3}$ School of Geography and water@leeds, University of Leeds, UK

${ }^{4}$ Applied Physics and Applied Mathematics Department, Columbia University in the City of New York, NY, United States ${ }^{5}$ Earth Science and Observation Center (ESOC), Cooperative Institute for Research in Environmental Sciences (CIRES),

Department of Geological Sciences, University of Colorado, CO, United States

${ }^{6}$ School of Earth and Environment, University of Leeds, UK

${ }^{7}$ Northumbria University, UK

${ }^{8}$ Department of Earth Sciences, Simon Fraser University, Burnaby, BC, Canada

${ }^{9}$ Department of Geology and Environmental Geosciences, University of Dayton, $\mathrm{OH}$, United States

${ }^{10}$ Water, Sediment, Hazards, and Earth-surface Dynamics (waterSHED) Lab, Department of Geoscience, University of

Calgary, AB, Canada

On 7 February 2021, a 25 million $\mathrm{m}^{3}$ rock/ice avalanche in Uttarakhand, northern India, developed into a far-reaching and devastating debris flow/debris flood, which we refer to as the 'Chamoli event'. Based on an extensive remote sensing-based geomorphological mapping campaign, the key mechanisms and characteristics of this process chain are largely, but not yet fully understood. Numerical mass flow simulations can help confirm or reject hypotheses regarding spatiotemporal aspects of flow evolution, its magnitude and dynamics, and therefore contribute to a better process understanding. More broadly, geomorphological mapping and numerical modelling of the Chamoli event help us to gain insights of the extent to which we are able to accurately simulate complex high-mountain geohazard process cascades. Such an understanding is invaluable for predictive modelling efforts targeted at informing disaster risk reduction strategies.

In the present work, we back-calculate the flow dynamics of the Chamoli event with three state-ofthe-art simulation models operating at different levels of complexity: (i) the one-phase mixture model RAMMS; (ii) the two-phase model GeoClaw, and (iii) the three-phase model r.avaflow. Input parameter sets are optimized against detailed reference data such as mapped trimlines and boulder locations, flow velocities and discharges obtained from video recordings, and erosion/deposition patterns derived by differencing pre- and post-event digital terrain models. The main aims of the study are to: (i) better understand the mechanisms of flow evolution of the 
Chamoli event; (ii) evaluate the level of model complexity that is necessary for accurating reproducing specific known characteristics of the process chain; and (iii) learn more about the sensitivity of model outputs to differences in initial conditions and model parameters, where these remain uncertain. The findings will facilitate the design of predictive modelling campaigns for hazard mapping purposes. 